\title{
Regionalization of the telencephalon in urodele amphibians and its bearing on the identification of the amygdaloid complex
}

\author{
Nerea Moreno ${ }^{1,2}$ and Agustín González ${ }^{1 *}$ \\ 1. Department of Cell Biology, Faculty of Biology, University Complutense of Madrid, Spain \\ 2. Department of Biology, Faculty of Sciences, University Autonoma of Madrid, Spain \\ Edited by: Javier DeFelipe, Cajal Institute, Spain \\ Reviewed by: Loreta Medina, Universidad de Lleida, Spain \\ Glenn R. Northcutt, University of California, USA
}

\begin{abstract}
The brain of urodele amphibians has formed the basis for numerous comparative neuroanatomical studies because its simplified arrangement of neurons and fibers was considered to represent the basic pattern common to all tetrapods. However, on the basis of classical histological techniques many common features shared by the brain of amniotes could not be identified in the anamniotic amphibians. Recently, the combined analysis of the chemoarchitecture and hodology has demonstrated that the brain, and particularly the telencephalon, of anuran amphibians shares all major basic features with amniotes. In the present study, we have conducted a series of immunohistochemical detections for telencephalic regional markers (nitric oxide synthase (NOS), $\gamma$-amino butyric acid (GABA), Islet-1 (Isl1), and Nkx2.1) that were useful tools for unraveling telencephalic organization in other vertebrates. In addition, the combination of tract-tracing techniques with dextran amines to demonstrate olfactory secondary centers, hypothalamic projections, and brainstem connections has served to propose subdivisions within the amygdaloid complex. The results of the present analysis of the urodele telencephalon using a multiple approach have demonstrated, among other features, the presence of a ventral pallial region, striatopallidal subdivision in the basal ganglia, and three main components of the amygdaloid complex. Therefore, in spite of its apparently simple organization, within the telencephalon of urodeles it is possible to identify most of the features observed in amniotes and anurans that are only revealed with the use of combined modern techniques in neuroanatomy.
\end{abstract}

Keywords: amygdala, pallium, subpallium, basal ganglia, homology, evolution

\section{INTRODUCTION}

Research over the last few years has proved that the combination of developing transcription factor expression pattern, tract-tracing techniques, and immunohistochemistry are powerful tools for comparing telencephalic territories among vertebrates. Thus, it has been demonstrated that the forebrain organization in amniotes (reptiles, birds, and mammals) shares main basic features, mostly analyzed following the prosomeric model (Puelles and Rubenstein, 2003). Moreover, in the last few years several studies have revealed that many characteristics of this prosencephalic organization can be found in anamniotes (amphibians and fishes) (Alunni et al., 2004; Bachy et al., 2001; Bachy et al., 2002; Hauptmann and Gerster, 2000; Milán and Puelles, 2000; Moreno et al., 2004; Moreno et al., 2005; Osorio et al., 2005; Osorio et al., 2006; Pombal and Puelles, 1999; Puelles et al., 1996; Wullimann and Puelles, 1999). In particular, the main components of the telencephalon have been identified in anuran amphibians, in which the four pallial regions (medial, dorsal,

\footnotetext{
* Correspondence: Agustín González, Department of Cell Biology, Faculty of Biology, University Complutense of Madrid, C/José Antonio Novais 2, Madrid E-28040, Spain. e-mail: agustin@bio.ucm.es

Received: 16 Aug. 2007; paper pending published: 23 0ct. 2007; accepted: 05 Dec. 2007; Published online: 30 Dec. 2007

Full citation: Frontiers in Neuroanatomy (2007) 1:1 doi: 10.3389/neuro.05/001.2007 Copyright (C) 2007 Moreno and González. This is an open-access article subject to an exclusive license agreement between the authors and the Frontiers Research Foundation, which permits unrestricted use, distribution, and reproduction in any medium, provided the original authors and source are credited.
}

lateral, and ventral), the septum, the striatopallidal system, and the amygdaloid complex were characterized (Brox et al., 2003; Brox et al., 2004; Endepols et al., 2006; Laberge et al., 2006; Marín et al., 1998a; Moreno and González, 2006; Moreno and González, 2007a).

Most data regarding telencephalic organization in amphibians have been gathered for anurans, which are usually regarded as being much more evolved than urodeles (ten Donkelaar, 1998). The central nervous system of urodeles is often considered to be primitive and simpler than one would expect based on their phylogenetic position among vertebrates (ten Donkelaar, 1998). Thus, many features of the brain seem to be less differentiated in urodeles than in tetrapod outgroups, including cartilaginous and bony fishes, and in some brain characters the urodele brain is even more simple than that of agnathans (Northcutt,1984; Northcutt,1987; Roth et al., 1992; Roth et al., 1993). This is particularly due to the limited cell migration from the ventricular lining that crowds most neurons into a dense central gray layer in which nuclei and distinct brain structures can be recognized, at best, as local condensations within this periventricular gray. However, several authors have suggested that the central nervous system in urodeles is characterized by secondary simplification, giving the impression that the brain is more primitive than those of other tetrapods (e.g., Northcutt, 1987; Roth et al., 1992; Roth et al., 1993). In particular, although the urodele telencephalon appears simple, it was possible to recognize virtually all main anatomical and functional components characteristic of the tetrapod telencephalon (Fritzsch, 1980; Herrick,1927; Herrick,1948; Northcutt, 1981; Northcutt and Kicliter, 1980; Roth, 1987; Roth et al., 1993). According to Northcutt and Kicliter (1980) these components would comprise the main and accessory bulbs, pallial (lateral, dorsal, and medial pallium), and subpallial 
(the septum and striatum) structures. In addition, although the boundaries between pallial and subpallial territories were not clear, it was already proposed that what was originally called amygdala (a caudal enlargement of the striatum, Herrick,1927; Herrick,1948) could be divided into a pallial component (pars lateralis of the amygdala) and a subpallial component (pars medialis of the amygdala).

In the present study, we have conducted a series of experimental approaches with the aim of further characterizing telencephalic regions in urodeles by means of the same technical tools that have served to identify their counterparts in anurans. Therefore, in the telencephalon of the urodele Pleurodeles walt, we first analyzed the immunohistochemical distribution of $\gamma$-amino butyric acid (GABA) and nitric oxide synthase (NOS), together with the transcription factors Nkx2.1 and Islet-1 (IsI1). This set of immunolabelings served to establish pallial versus subpallial derivatives and also helped in the identification of subterritories within the main telencephalic regions. A second main goal in this study was to identify the main amygdaloid components (lateral, medial, and central), as defined for anurans (Moreno and González, 2006; Moreno and González, 2007a). To achieve this goal, the relation of the olfactory information, the hypothalamic connections, and the projections to the brainstem of the amygdaloid components were analyzed by combining tract-tracing techniques with dextran amines and immunohistochemistry for transcription factors and neurotransmitters.

\section{MATERIALS AND METHODS \\ Animals and tissue processing}

For the present study, 18 juvenile and adult specimens of newts ( $P$. walt $)$ were used. The animals were obtained from the laboratory stocks of the Department of Cell Biology, University Complutense of Madrid. The original research reported herein was performed according to the regulations and laws of the European Union (86/609/EEC) and Spain (Royal Decree 223/1998) for care and handling of animals in research. In all the cases, prior to perfusion the animals were deeply anesthetized in a $0.4 \mathrm{mg} / \mathrm{ml}$ solution of tricaine methanesulfonate (MS222, Sigma Chemical Co., St. Louis, M0).

\section{In vitro tracing techniques}

The animals, under anesthesia, were perfused transcardially with iced Ringer's solution ( $75 \mathrm{mM} \mathrm{NaCl}, 25 \mathrm{mM} \mathrm{NaHCO}_{3}, 2 \mathrm{mM} \mathrm{CaCl}, 0.5 \mathrm{mM}$ $\mathrm{MgCl}_{2}, 11 \mathrm{mM}$ glucose; Merck), which was oxygenated with carbogen $\left(95 \% \mathrm{O}_{2}, 5 \% \mathrm{CO}_{2}\right)$, to a pH of 7.3 . Subsequently, the brains were isolated and, after removal of the dura mater and the choroid plexuses, transferred to fresh iced Ringer's solution. The tracers $3 \mathrm{kD}$ biotinylated dextran amine (BDA; Molecular Probes) or $3 \mathrm{kD}$ fluorescein-conjugated dextran amine (FDA; Molecular Probes) were used because they are transported faster than dextran amines of higher molecular weights. Iontophoretic injections were made unilaterally with a 4-6 $\mu$ A positive pulsed current (7 seconds on $/ 7$ seconds off) applied to the tracer solution (10\% BDA or FDA in $0.9 \mathrm{NaCl}$ ) in a glass micropipette (diameter 5-10 $\mu \mathrm{m}$ ) for a period of 10-15 minutes. Injections were placed into the olfactory bulbs, the hypothalamus or the parabrachial area in the brainstem. The brains were maintained for 24 hours at $4^{\circ} \mathrm{C}$ in continuously oxygenated Ringer's solution. The brains were then fixed for 24-48 hours in a $4 \%$ paraformaldehyde in phosphate buffered solution (0.1 M; pH 7.4; PB) and immersed in a solution of $30 \%$ sucrose in PB for $5-8$ hours at $4^{\circ} \mathrm{C}$. They were then blocked in a solution of $20 \%$ gelatin and $30 \%$ sucrose in PB and stored overnight at $4{ }^{\circ} \mathrm{C}$ in a solution of $4 \%$ formaldehyde and $30 \%$ sucrose in PB. Sections were cut on a freezing microtome at $30 \mu \mathrm{m}$ thickness in the transversal or sagittal plane and collected in cold PB. BDA was visualized by incubation with Oregon Green streptavidin complex (1:500; Molecular Probes), an Alexa 594-conjugated streptavidin complex (1:500; Molecular Probes), or AMCA streptavidin complex (1:100 Vector) for 90 minutes in all the cases. The sections were then mounted on glass slides and coverslipped with Vectashield (Vector Labs, Burlingame, CA).

\section{Immunochemistry}

To characterize the urodele telencephalic regions, immunohistochemistry for GABA, Nkx2.1, NOS, and Isl1 was conducted. In all the cases, the anesthetized animals were perfused transcardially with saline followed by $4 \%$ paraformaldehyde in $0.1 \mathrm{M} \mathrm{PB}$. For the immunohistochemical procedures, after blocking, cutting, and rinsing the brain sections were incubated in primary antibody solutions for $36-48$ hours at $4^{\circ} \mathrm{C}$. All primary antibodies were diluted in $5-10 \%$ normal serum in PB with $0.1 \%$ Triton X-100 (Sigma, St. Louis, M0) and 2\% bovine serum albumin (BSA, Sigma). The serum used in each case corresponded with the species in which the secondary antibody was raised.

GABA, Nkx2.1, Is/1, and NOS immunohistochemistry. Immunohistochemical procedures were carried out as follows: (1) incubation for 72 hours at $4{ }^{\circ} \mathrm{C}$ in the following solution of each primary antibody: rabbit anti-GABA (Sigma, code A2129) diluted 1:3000, rabbit anti-Nkx2.1 (Biopat Immunotechnologies, code PA 0100, Caserta, Italy) diluted 1:1000, mouse anti-IsI1 (Hybridoma bank, code 39.4D5, Iwoa) diluted 1:500, and sheep anti-NOS (K205 antibody; kindly donated by Dr. P.C. Emson, The Babraham Institute, Cambridge, United Kingdom) diluted 1:20 000; (2) goat anti-rabbit Alexa 594 (Molecular Probes) diluted 1:500, goat antimouse Alexa 488 (Molecular Probes) diluted 1:500, or donkey anti-sheep rhodamine (Chemicon) diluted 1:100 for 90 minutes at room temperature. After rinsing the sections were mounted on glass slides and coverslipped with Vectashield (Vector, Burlingame, CA).

All the primary antibodies have been previously tested in amphibians and used as territory markers in the forebrain (Bachy and Rétaux, 2006; González et al., 2002a; González et al., 2002b; Marín et al., 1998a; Moreno and González, 2003; Moreno and González, 2004; Moreno and González, 2007b; Moreno and González, 2005a). General controls for the immunohistochemical reaction included: (1) staining some selected sections with pre-immune rabbit serum; (2) controls in which either the primary or the secondary antibody was omitted. In all these negative controls, the immunostaining was eliminated.

The anti-GABA antibody was developed in rabbit using GABA-BSA as the immunogen. The antibody was isolated from antiserum by immunospecific methods of purification and antigen specific affinity isolation removes essentially all rabbit serum proteins, including immunoglobulins that do not specifically bind to GABA. Rabbit antiGABA shows positive binding with GABA in a dot blot assay, and negative binding with BSA. Previously, the same antibody has been used in amphibians (Bachy and Rétaux, 2006; Moreno and González, 2007b) with comparable successful results.

Thyroid transcription factor 1 (known as TTF-1, Nkx2.1, or T/EBP) is a homeodomain containing transcription factor expressed in thyroid and lung epithelium and in restricted regions of the fetal brain (Kimura et al., 1996; Lazzaro et al., 1991). The anti-Nkx2.1 was prepared against a synthetic peptide derived from the sequence of the rat protein (epitope corresponding to amino acids 110-122 at the amino terminus of rat TTF-1) and was affinity purified. It gives a specific nuclear staining on TTF-1 containing human, chicken, rat, mouse, or Xenopus tissues. In previous studies, the same antibody has been used in anurans (Bachy and Rétaux, 2006; González et al., 2002a; González et al., 2002b; Moreno and González, 2007b) and also in many other tetrapods (Bachy and Rétaux, 2006; Carrillo and Doupe, 2004; Corbin et al., 2003; Marín et al., 2000) with comparable successful results, supporting the conservation of this transcription factor in the evolution. In addition, previous studies in developing Xenopus using in situ hybridization (Bachy et al., 2002) and immunohistochemistry with this antibody (Bachy and Rétaux, 2006) to evidence the Nkx2.1 expression have demonstrated the fully comparable results with both techniques. Pre-adsorption of the primary antisera with synthetic Nkx2.1 peptide (Biopat; 0100-P) at $0.1,1.0$, or $10.0 \mu \mathrm{M}$, eliminated the immunostaining.

The anti-Isl 1 antibody was generated in mouse against a $25 \mathrm{kDa}$ peptide derived from the C-terminal portion of rat Isl1. The antibody was 
generated by the Thomas M. Jessell laboratory (Columbia University, Howard Hughes Medical Institute, 701 W. 168th St., Rm. 1013, New York, NY 10032) and successfully tested for rat, mouse, chick, frog, and zebra fish. In amphibians it showed fully comparable staining results in all the species tested. Therefore, for the present study, in which the comparison with different species is important, the use of the same antibody seemed the most convenient choice.

Finally, the specificity of the NOS antiserum was previously described (Herbison et al., 1996). This antibody recognizes neuronal NOS using Western blotting and the immunoreactivity is abolished by absorption of the K205 antiserum with recombinant neuronal NOS protein (1 mM overnight at $4^{\circ} \mathrm{C}$ ). In addition, this antibody proved to reveal specifically neuronal NOS in mammalian, as well as in reptilian and amphibian tissues (González et al., 1996; Moreno et al., 2002; Muñoz et al., 2000; Smeets et al., 1997).

Double immunohistochemistry. Double immunohistochemical procedures were carried out as follows: (1) incubation for 72 hours at $4{ }^{\circ} \mathrm{C}$ in the following solutions of each primary antibody cocktails with the same concentrations as described before: rabbit anti-GABA/mouse anti-Isl1, sheep anti-NOS/mouse anti-Isl1, and anti-GABA/sheep anti-NOS; (2) incubation for 90 minutes at room temperature in the following solutions of secondary antibody cocktails: goat anti-rabbit Alexa 594 (1:500)/goat anti-mouse Alexa 488; donkey anti-sheep Rhodamine (1:100)/chicken anti-mouse Alexa 488 (1:500), and chicken anti-rabbit Alexa 488 (1:500)/ donkey anti-sheep Rhodamine (1:100). After rinsing the sections were mounted on glass slides and coverslipped with Vectashield (Vector).

The sections were analyzed with a Zeiss fluorescence microscope with appropriate filter combinations. Selected sections were photographed using a digital camera (Coolpix 930, Nikon). Contrast and brightness were adjusted using Adobe PhotoShop 7.0 (Adobe Systems, San Jose, CA).

\section{Combined tract-tracing/immunohistochemical experiments}

In this last set of experiments, dextran amine injections in the olfactory bulbs and/or ventral hypothalamus was combined with immunohistochemistry for NOS or GABA. For the double tract-tracing experiments, two different dextran amines were simultaneously injected: FDA and BDA. After brain processing (see above), BDA was revealed with Alexa 594conjugated streptavidin complex (1:500; Molecular Probes). For the triple tract-tracing/immunohistochemistry experiments, the two dextran amines were injected as described before and, after brain processing, immunohistochemistry for NOS or GABA was conducted. The final step for visualization of the triple fluorescence was accomplished for 90 minutes at room temperature with the following cocktail: donkey anti-sheep Rhodamine (1:100; Chemicon)/AMCA streptavidin complex (1:100; Vector) and goat anti-rabbit Alexa 594 (1:500; Molecular Probes)/ AMCA streptavidin complex (1:100; Vector), respectively.

\section{RESULTS}

\section{The telencephalon of Pleurodeles waltl Normal histology}

The relatively large telencephalic hemispheres of Pleurodeles are formed by thin walls around the large lateral ventricles (Figure 1a). In Nisslstained material, most cells appear grouped around the ventricle, leaving a superficial thick layer mainly constituted by fibers. This poorly differentiated cytoarchitecture corresponds in all areas with a pattern of organization in which the periventricularly located neurons extend their dendrites outward, where they spread widely in the overlying fiber zone (Figure 1b). In the latter zone, the application of tract-tracing techniques reveals that many fiber systems are organized (Figure 1c), in a manner that most of the synaptic contacts occur between these fibers and the dendritic arborizations formed in the peripheral layer.

Following topographical criteria, and according to Northcutt and Kicliter (1980) for other urodele species, the main subdivisions to be taken into consideration in the telencephalon would include the main and accessory olfactory bulbs and pallial and subpallial territories. Within the pallium, the medial pallium is the region that shows more cell migration and is thicker than the rest of the pallium. The dorsal pallium, that constitutes most of the roof of the hemisphere, shows a densely packed periventricular cell layer but also an intermediate cell layer with scattered neurons (Figure 1a). The lateral pallium represents the dorsal portion of the lateral wall and is the pallial region with less cell migration from the ventricle. The boundaries between the lateral pallium and the ventrally located striatum are particularly unclear and only at caudal levels a cell prominence (lateral cell prominence; Icp) marks their borders.

The striatum and the amygdala occupy the ventral portion of the lateral hemisphere at rostral and caudal levels, respectively (Figure 1a). While the striatum was considered as a clear subpallial structure, within the amygdala two parts were considered and separated by a ventral cellular prominence (vcp), the pars lateralis (Apl; currently MeA) which was regarded as a pallial structure and the pars medialis (Apm) of subpallial origin (Northcutt and Kicliter, 1980). The hemispheric wall is finally formed in its ventromedial portion, at mid-rostral levels, by the nucleus accumbens (a medial continuation of the striatum at rostral levels), and the septum, which shows a layered arrangement of migrated cells from the ventricle (Figure 1a).

Within this framework of roughly defined telencephalic regions the results of our experimental study will be presented and analyzed in the following sections.

\section{Regional markers: telencephalic expression of NOS, Isl1, GABA, and Nkx2.1}

The combined analysis of these four territorial markers in the telencephalon of Pleurodeles allowed us to identify new subdivisions within the pallium, the basal ganglia, and the amygdala.

NOS immunohistochemistry. Distinct patterns of immunoreactivity were found in the telencephalon. In the medial, dorsal, and lateral pallial regions only scattered cells were labeled among the periventricular or more migrated neurons (Figure 2a). This situation strikingly contrasted with the pattern observed in the region that would correspond with the ventral portion of the classical lateral pallium. In this position, strongly immunoreactive nitrergic cells were densely packed and their laterally directed processes formed a conspicuous neuropil (Figure 2a,a') along the rostrocaudal extent of the hemisphere, although the densest immunoreactivity was found at caudal levels. From these NOS-positive cells a caudally directed fiber tract was labeled coursing ventrolaterally around the central striatal neuropil. This region was readily comparable to the ventral pallium, i.e., the fourth pallial region recently identified in tetrapods (Brox et al., 2004; Moreno et al., 2004; Puelles et al., 2000; Smith Fernández et al., 1998). Thus, by comparison with results in anurans, it would be homologous to the pallial component of the amygdala, which is termed the lateral amygdala (LA; Moreno and González, 2004). Within the striatum, at rostral telencephalic levels, only scattered cells were found. However, at the caudal tip of the striatum a group of large and densely NOS immunoreactive cells were observed (Figure 2a), making this region distinct from the rostral striatal region and, therefore, putatively homologous to the similarly located large NOSpositive cells of the central amygdala (CeA; Moreno and González, 2005a) was considered. Some weakly NOS immunoreactive cells were also dispersed in ventromedial telencephalic regions but their distribution did not allow further distinction of particular zones.

Is/1 immunohistochemistry. The analysis of the distribution of this marker facilitated the localization of subpallial derivatives and, in particular, those derived from the lateral ganglionic eminence (LGE, striatal regions), as compared with amniotes (Stenman et al., 2003) and anuran amphibians. The Isl1 distribution pattern in Pleurodeles strongly highlighted striatal territories that could be easily depicted by the large number of IsI1-expressing cells that occupied most of the periventricular cell layer, but avoided the ventricular zone (Figure $\left.2 b, b^{\prime}\right)$. The pallial/ 


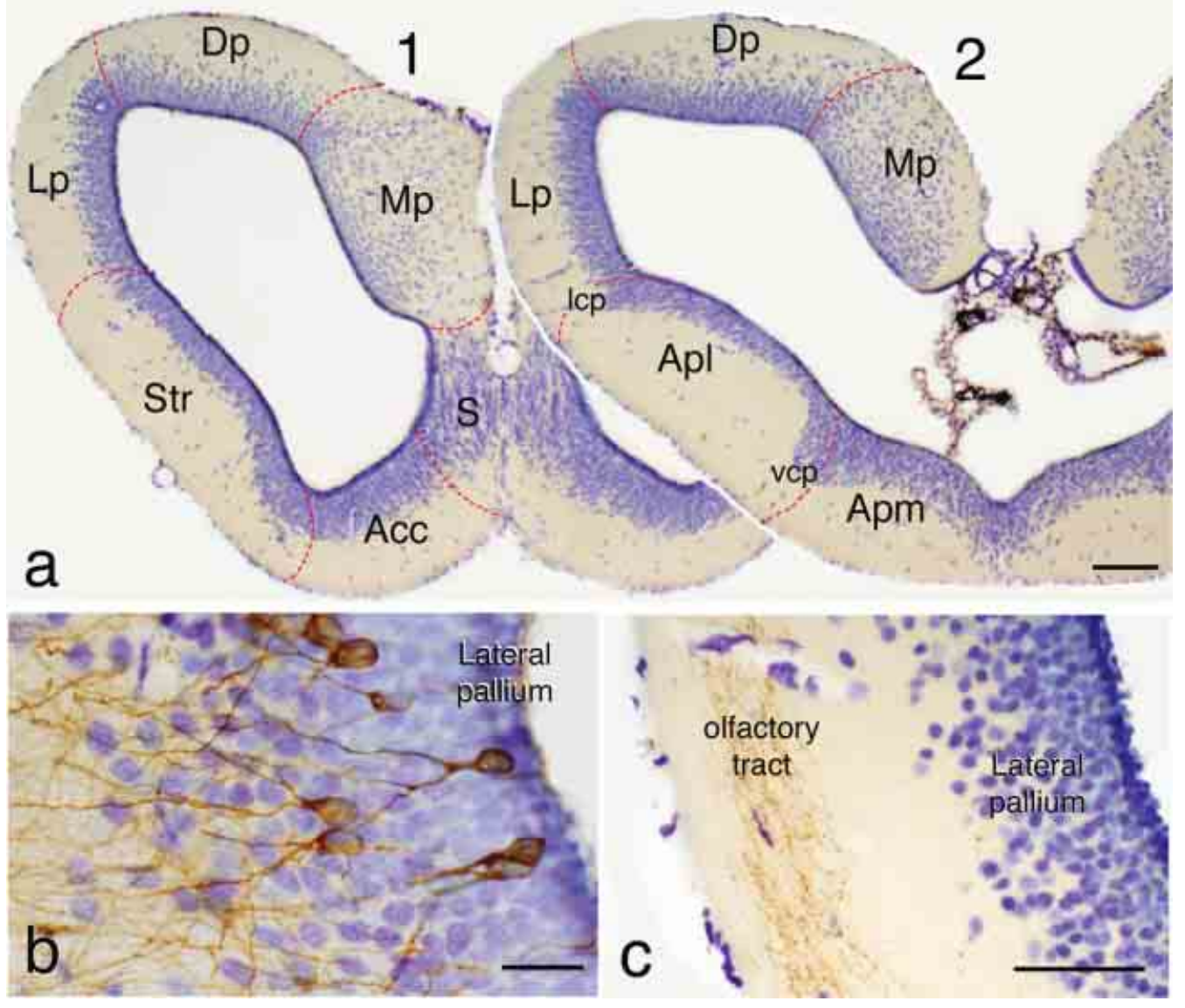

Figure 1. (a) Rostral (1) and caudal (2) transverse sections through the telencephalic hemisphere of $P$. waltl showing in a Nissl-staining with cresyl violet its general appearance and the rough demarcation of its main regions. (b) Detail of the lateral pallium in a section in which some neurons were retrogradely labeled with BDA from the medial pallium showing their common morphology of somata in the periventricular cell layer and dendritic arborizations extending toward the superficial fiber layer. (c) Photograph of the lateral pallium showing BDA-labeled fibers from the olfactory bulb in the olfactory tract located in the peripheral fiber layer. Scale bars $=200 \mu \mathrm{m}$ (a), $50 \mu \mathrm{m}$ (b), and $100 \mu \mathrm{m}$ (c). Acc, nucleus accumbens; Apl, amygdala pars lateralis; Apm, amygdala pars medialis; BST, bed nucleus of the stria terminalis; $C e A$, central amygdala; Dp, dorsal pallium; LA, lateral amygdala; Icp, lateral cellular prominence; LGE, lateral ganglionic emunence; Lp, lateral pallium; MeA, medial amygdala; MGE, medial ganglionic eminence; Mp, medial pallium; Pa, pallidum; S, septum; Str, striatum; vcp, ventral cellular prominence; VP, ventral pallium.
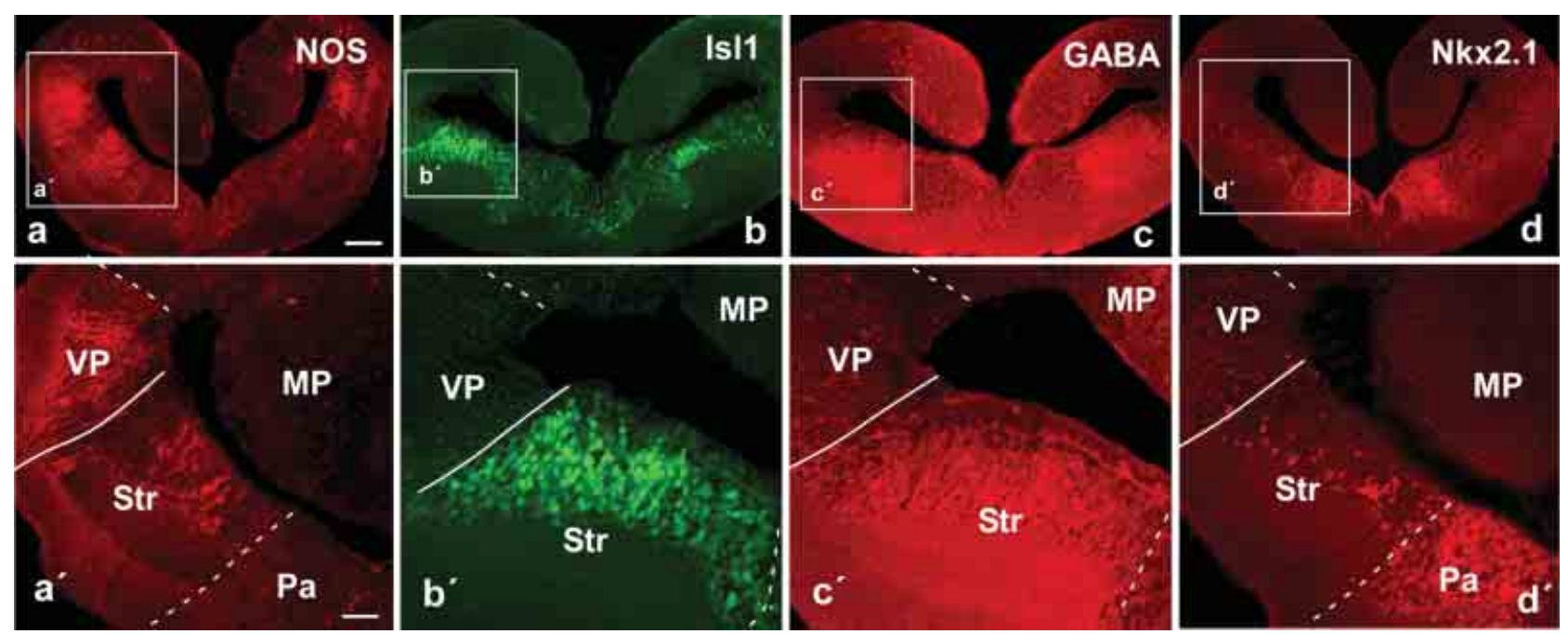

Figure 2. Photomicrographs of transverse sections through the caudal portion of the lateral telencephalic wall of $P$. walt illustrating by immunohistochemistry the expression at these levels of NOS (a), Is/1 (b), GABA (c), and Nkx2.1 (d). Low (a-d) and high (á-d) magnification photographs are presented. Scale bars $=200 \mu \mathrm{m}$ $(a-d)$ and $100 \mu \mathrm{m}\left(a^{\prime}-d^{\prime}\right)$. Abbreviations as in Figure 1. 
subpallial boundary was demarcated along the rostrocaudal telencephalic levels and the double labeling experiments for NOS/Isl1 confirmed in Pleurodeles the pallial location of the putative LA and the striatal nature of the proposed CeA (Figures $2 a, a^{\prime}, 2 b, b^{\prime}$, and $\left.3 d-3 f, d^{\prime}, f^{\prime}\right)$. Cells immunoreactive for Isl were also dispersed in more ventromedial zones (Figure $2 b$ ), i.e., in areas derived from the medial ganglionic eminence (MGE, see below).

GABA immunohistochemistry. The distribution of GABA in the telencephalon of Pleurodeles outlined subpallial territories and, in particular, those of the striatal derivatives (Figures 2c, $\mathbf{c}^{\prime}$ and $3 \mathrm{~b}$ ). Scattered immunoreactive cells were also detected in pallial regions but in a pattern completely distinct from that of the subpallial regions. The double immunohistochemistry for GABA/IsI1 confirmed the relationship between both the markers in subpallial territories (Figures $3 a-3 c$, and $\left.3 a^{\prime}-c^{\prime}\right)$.

Nkx2.1 immunoreactivity. Neurons expressing the transcription factor Nkx2.1 were mainly located in the ventromedial telencephalon (Figure $2 \mathrm{~d}, \mathrm{~d}^{\prime}$ ). At caudal levels, they corresponded to pallidal derivatives that arise from the MGE, as established for amniotes and anurans (González et al., 2002a; González et al., 2002b; Puelles et al., 2000). At rostral levels, Nkx2.1-labeled cells were primarily distributed in the septum. Of note, scattered cells were observed in the striatum and the Apl (currently MeA) and these cells were always detached from the ventricle, allowing a clear distinction between the dorsolateral striatal territory and the ventromedial pallidal territory (Figure $2 \mathrm{~d}^{\prime}$ ).

The combined analysis of the four territorial markers strongly suggested the existence of a ventral pallial region and subdivisions within the basal ganglia (striatal and pallidal components) and the amygdaloid complex. The latter would be composed by pallial and subpallial components and, to characterize further their significance, their relationship with olfactory information, the hypothalamus, and the brainstem was analyzed.

\section{Olfactory bulbs projections and hypothalamic connections}

The identification of the secondary olfactory centers (receiving both olfactory and vomeronasal information) and their connections with the hypothalamus has served to characterize distinct amygdaloid components in amniotes and anurans (Lanuza et al., 1997; Martínez-García et al.,
2006; Moreno and González, 2005b). Therefore, in a series of experiments we anterogradely labeled the olfactory tracts from the olfactory bulbs and, simultaneously, observed retrogradely labeled cells from the hypothalamus. We analyzed these two labelings also in combination with NOS and GABA immunohistochemistry (Figures 4 and 5).

Tracer injections into the olfactory bulbs (both the main and the accessory bulbs) labeled the course followed by the fibers in the olfactory tracts, mainly in the lateral hemispheric wall (Figure 4) in a manner similar to that previously reported for urodeles (Royce and Northcutt, 1969; Schmidt and Roth, 1990), although connections with the medial telencephalic wall or the habenula were very restricted, also in concordance with recent experimental data (Laberge and Roth, 2005). The olfactory information always ran in the lateral tract situated in the outer part of the hemisphere reaching the dorsolateral pallium and, mainly at caudal levels, extensive subpallial regions (Figures $4 a$, and $5 a, b)$. In these experiments, it was demonstrated that the olfactory information could be relayed to the hypothalamus from two main regions. First, a small number of cells projecting to the hypothalamus were observed in the ventral portion of the lateral pallium, medially located to the olfactory tract (asterisks in Figures $4 \mathrm{~b}, 4 \mathrm{c}$, and $5 \mathrm{c}^{\prime}, \mathrm{d}$ ).

These cells were shown to be located within the intense NOS immunoreactive region proposed as the ventral pallium (Figures $5 \mathrm{e}-5 \mathrm{~h}$ ). The second group of hypothalamic projecting neurons was found in the subpallium, according to the triple labeling with NOS and GABA (Figures $4 b, 4 c$, and $5 c-5 h$ ). Notably, the majority of the cells labeled from the hypothalamus at caudal telencephalic levels were located in the ventromedial portion of the classically named $\mathrm{Apl}$ (currently MeA) and were related to the ventral most part of the olfactory fibers (Figure $4 c, c^{\prime}$ ), where the vomeronasal fibers course (Laberge and Roth, 2005).

\section{Brainstem connections}

In amniotes and anurans, the amygdaloid complex is related with different brainstem autonomic centers and the spinal cord through the "autonomic amygdala", i.e., a striatal derivative called the CeA (Martínez-García et al., 2006; Moreno and González, 2005a; Moreno and González, 2006). Thus, in the last set of experiments, large dextran amine injections were placed in the parabrachial region of Pleurodeles and the labeled structures in the telencephalon were analyzed in combination with GABA and NOS immunohistochemistry (Figure 6). All injections resulted in large numbers
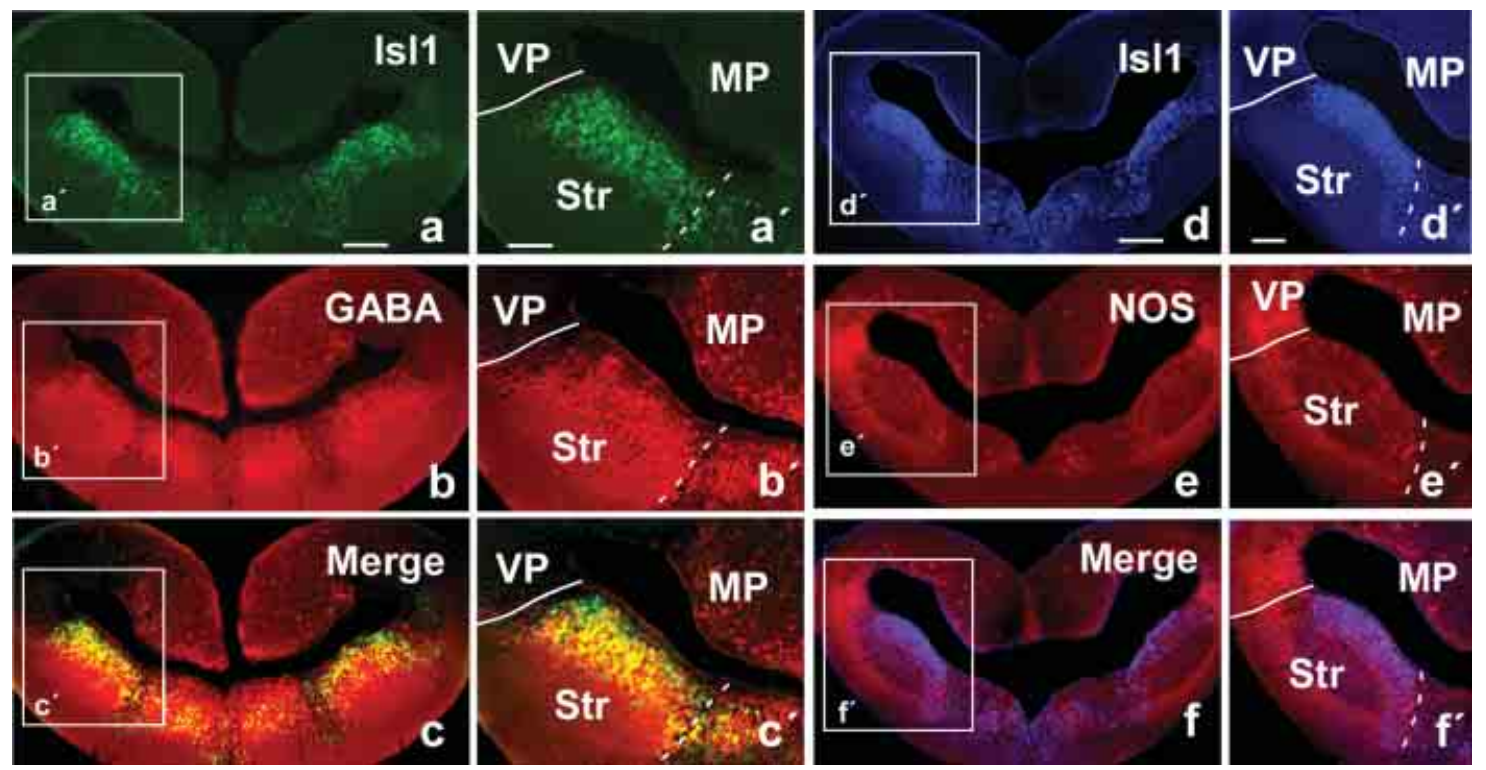

Figure 3. Photomicrographs of transverse sections through the caudal portion of the lateral telencephalic wall of $P$. walt illustrating in the same section the staining for IS/1 (a) and GABA (b) and the combination of both (c). Similarly, Is/1 (d) and NOS (e) are shown in a same section, as well as the combination of both (f). Low $(a-f)$ and high $\left(a^{\prime}-f^{\prime}\right)$ magnification photographs are presented. Scale bars $=200 \mu \mathrm{m}(a-f)$ and $100 \mu m\left(a^{\prime}-f^{\prime}\right)$. Abbreviations as in Figure 1. 

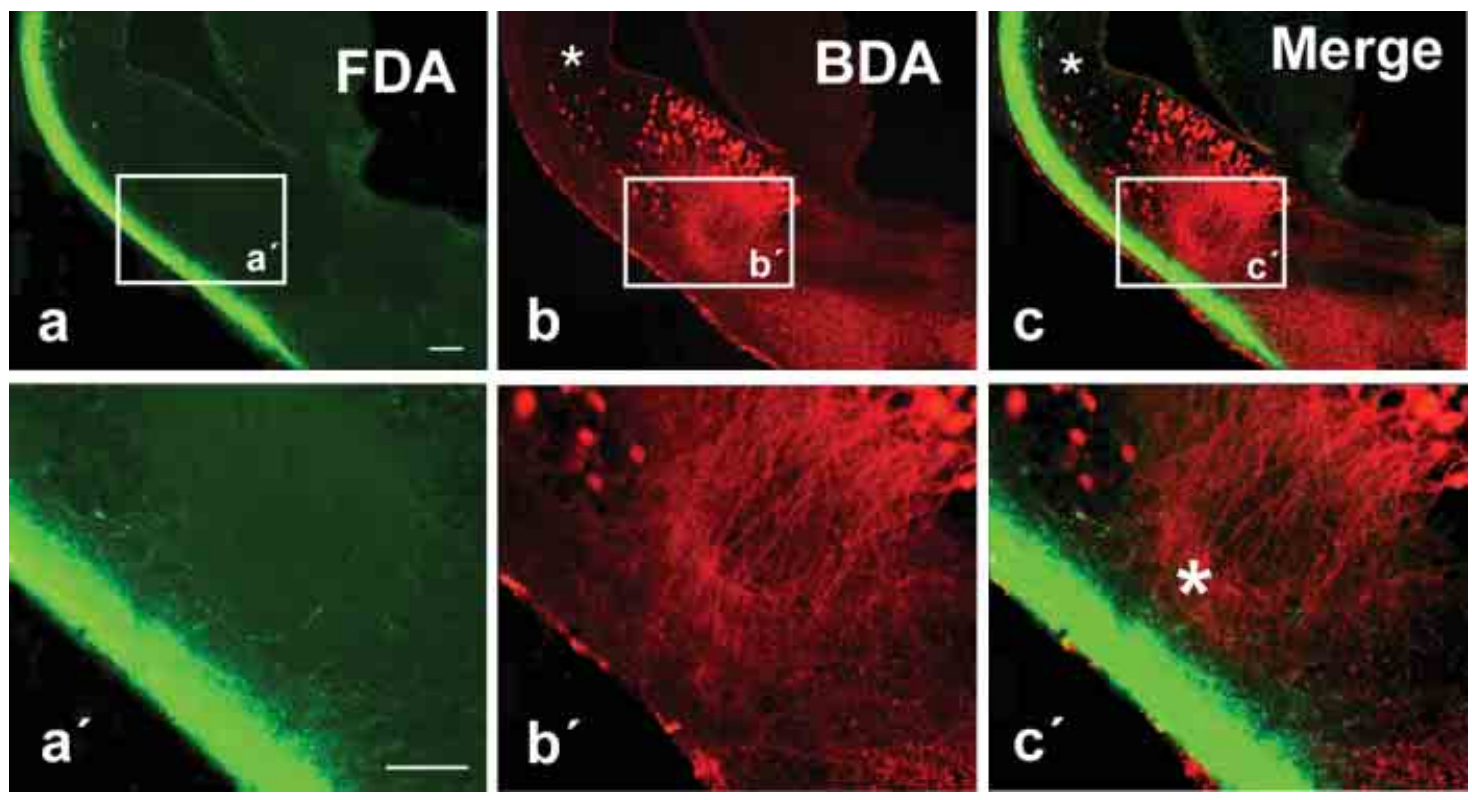

Figure 4. Photomicrographs showing labeled cells and fibers in transverse sections in the $\mathrm{P}$. waltl caudal telencephalon at low (a-c) and high $\left(\mathrm{a}^{\prime}-\mathrm{c}^{\prime}\right)$ magnification. (a) Olfactory tract fibers after FDA injection into the olfactory bulb. (b) Cells and fibers labeled in the lateral telencephalon after BDA injection into the ventral hypothalamus. (c) Double-labeled section (the same as in a and b) showing simultaneously the terminal neuropil formed by axons from the olfactory bulb (green) and the labeled cells in the lateral telencephalon that project to the hypothalamus (red). Small asterisks (b,c) mark scattered cells retrogradely labeled in the ventral pallium and large asterisk ( $\left.c^{\prime}\right)$ marks the extending dendrites extending toward the olfactory tract. Scale bars $=200 \mu \mathrm{m}$.

of retrogradely labeled cells in the ventrocaudal striatal area, surrounded by abundant fiber and terminal-like labeling that corroborated a bidirectional connection (Figure 6a). The combination with GABA immunohistochemistry served to confirm that the retrogradely labeled cells were located in the subpallium within the striatal region (Figure 6b). Moreover, the double labeling experiments for NOS immunohistochemistry revealed that most cells in the caudal striatal region were located where the large NOS positive cells were found (Figure $6 c$ ), strengthening the comparison of this region with the CeA of anuran amphibians (see above).

\section{DISCUSSION}

The telencephalon of urodele amphibians shows an apparently simple organization when studied by classical histological techniques. Clear boundaries between regions are not observed and the existence of telencephalic components present in the brain of amniotes cannot be assessed. Therefore, the multiple approach used in this study by means of immunohistochemical and tract-tracing techniques seems necessary to establish more precise regionalization of the telencephalon that allows the comparison with their counterparts in other tetrapods. The present analysis has served to highlight the existence of several "new" regions which demonstrate that in the telencephalon of urodeles all major subdivisions found in other tetrapods can be recognized (Puelles et al., 2000).

The main results of this analysis included the identification of the pallial/subpallial boundary, the presence of a ventral pallial region, a striatopallidal system, and distinct components of the amygdaloid complex.

\section{Regionalization of the urodele telencephalon}

The choice of the four markers used in this study (NOS, GABA, Isl1, Nkx2.1) was prompted by their known implications in the development of distinct telencephalic subdivisions and phenotype specification in other tetrapods. Especially, Isl1 is implicated in the general basal forebrain organization (phenotype acquisition, pathfinding, and neural differentiation; for review see Hobert and Westphal, 2000). We opted for GABA as a subpallial neuronal differentiation marker, as results from the last few years have indicated that telencephalic GABAergic neurons are generated in the Dlx-expressing subpallium (Brox et al., 2003; Bulfone et al., 1993; Marín and Rubenstein, 2001; Price et al., 1991). In addition, we used the transcription factor Nkx2.1 because it is an essential regulator of the MGE (Sussel et al., 1999) and acts in the specification of this telencephalic subdivision that gives rise to the pallidum. The combination of them (Isl1, GABA, and Nkx2.1) allowed the clear visualization of the pallial/subpallial boundary, and the limits of the MGE and LGE. In anurans, the ventropallial amygdaloid area, the LA, corresponded to a rostrocaudal band throughout the length of the lateral wall of the hemisphere, related to a ventricular bulge, clearly delineated by NOS immunohistochemistry (Moreno and González, 2004; Moreno and González, 2006); thus the distribution of NOS constitutes a very useful tool for identifying the putative pallial amygdaloid areas. Finally, the combination of all these markers with the tract-tracing experiments, allowed us to clearly delineate the urodele telencephalon and identify the putative amygdaloid territories in comparison to those described in anurans and amniotes (Figure 7).

Our results extend previous data obtained in the analysis of the urodele telencephalon based on diverse approaches in the recent years (Marín et al., 1997a; Marín et al., 1997b; Marín et al., 1997c; Laberge and Roth, 2005). We found that Nkx2.1, IsI1, GABA, and NOS are expressed in unique and conserved patterns that mark specific regions of the telencephalon. This situation allowed us to analyze the boundary of particular areas and nuclei of the brain that could be identified by their expression patterns (Figure 7). At subpallial levels, the combination of GABA, Isl1, and Nkx2.1 delineates the limits of the eminences, LGE and MGE, which give rise to the striatum and pallidum, respectively. In particular, the pallidal component is revealed by Nkx2.1 expression, which is also directly involved in the patterning of the subpallial telencephalon and hypothalamus (Marín et al., 2002; Shimamura and Rubenstein, 1997; Sussel et al., 1999). In all tetrapods studied, Nkx2.1 is expressed in both progenitor and postmitotic cells and its expression is often maintained into 

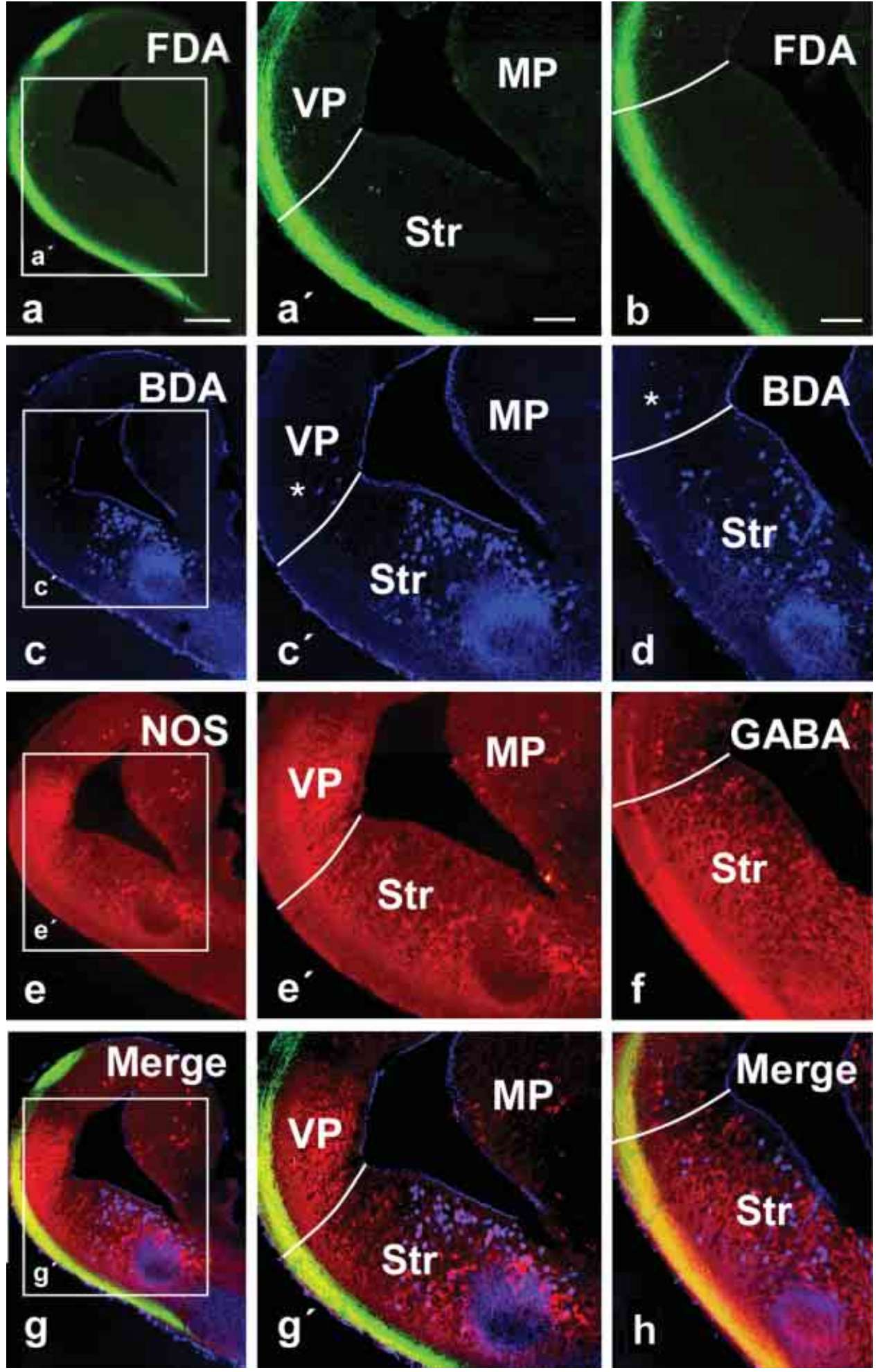

Figure 5. Photomicrographs showing labeled cells and fibers in transverse sections with simultaneous triple labeling in the $P$. waltl caudal telencephalon at low $(\boldsymbol{a}-\boldsymbol{h})$ and high $\left(\boldsymbol{a}^{\prime}, \boldsymbol{c}^{\prime}, \boldsymbol{e}^{\prime}, \boldsymbol{g}^{\prime}\right)$ magnification. $(\mathbf{a}, \boldsymbol{b})$ Olfactory tract fibers after FDA injection into the olfactory bulb. (c, d) Cells and fibers labeled in the lateral telencephalon after BDA injection into the ventral hypothalamus. (e) NOS expression in the telencephalon. (f) GABA expression in the telencephalon. (g) Triple-labeled section (the same as in a, c, and e) showing simultaneously the terminal neuropil formed by axons from the olfactory bulb (green), the labeled cells in the lateral telencephalon that project to the hypothalamus (blue), and the NOS expression (red). (h) Triple-labeled section (the same as in b, $d$, and f) showing simultaneously the terminal neuropil formed by axons from the olfactory bulb (green), the labeled cells in the lateral telencephalon that project to the hypothalamus (blue), and the GABA expression (red). Asterisks mark scattered cells retrogradely labeled in the ventral pallium. Scale bars $=200 \mu \mathrm{m}(\mathrm{a}-\mathrm{g})$, $100 \mu \mathrm{m}\left(a^{\prime}-g^{\prime}, b^{\prime}-h^{\prime}\right)$. Abbreviations as in Figure 1. 

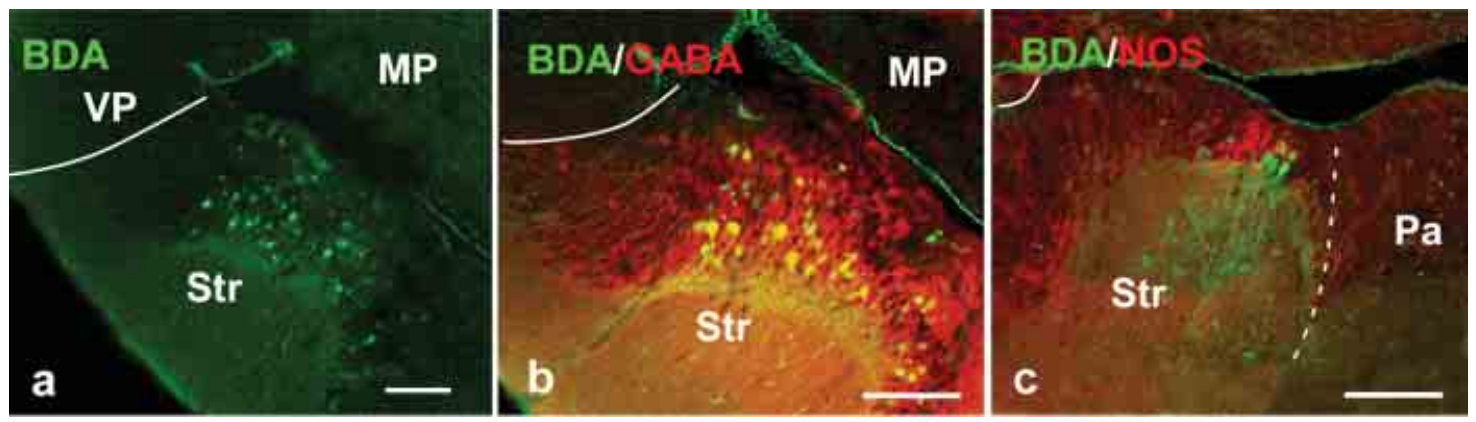

Figure 6. Photomicrographs showing labeled cells and fibers in transverse sections in the $\boldsymbol{P}$. walt/ caudal telencephalon showing (a) anterogradely labeled fibers and retrogradely labeled neurons at striatal levels after BDA injection into the parabrachial area; (b,c) double-labeled sections showing simultaneously the anterograde fibers and retrograde projection neurons at caudal striatal levels after a BDA injection into the parabrachial area (green) and the GABA (red; $\boldsymbol{b})$ and NOS (red; $\boldsymbol{c}$ ) expression.Scale bars = $100 \mu \mathrm{m}$. Abbreviations as in Figure 1.

adulthood, suggesting it has a role both in the specification of precursors and in the differentiation or maintenance of the phenotype mature ventral forebrain cells (Bachy et al., 2002; González et al., 2002a; González et al., 2002b; Marín et al., 2000; Puelles et al., 2000). Our results in Pleurodeles are consistent with those described in other tetrapods; thus Nkx2.1 is expressed by virtually all the MGE cells and scattered cells were also detected in LGE territories that most likely correspond to migrated cells from the MGE, like in amniotes and anurans (Bachy and Rétaux, 2006; Marín et al., 2000). Of note, in a recent article based on connectivity, the main pallidal region was proposed to be included in the large intermediate striatum of salamanders (Laberge and Roth, 2005). However, in the same study the difficulty of this homology was pointed out and the authors questioned the alternative hypothesis in which the functional equivalents to the pallidal areas could be found in the region below the vcp, what fully concurs with our present results in Pleurodeles. In the case of GABA, it has been pointed out that the production of GABAergic neurons in the rostral forebrain is largely restricted to specific histogenetic territories that express developmental regulatory genes of the Dlx family (Bulfone et al., 1993; Marín and Rubenstein, 2001; Price et al., 1991); thus it constitutes an extremely useful tool in the study of prosencephalic boundaries. Our results are in line with previous data in tetrapods, in which GABAergic cells are densely concentrated in the telencephalic basal ganglia (Brox et al., 2003; Endepols et al., 2007; Guirado et al., 1999; Katarova et al., 2000; Medina and Reiner, 1995; Marín et al., 1998b; Reiner et al., 1984; Reiner et al., 1998). In addition, the dispersed GABAergic cells found in the telencephalic pallium of amniotes and anurans are produced in the Dlx- expressing subpallium and enter the pallium during development by way of a tangential migration (Anderson et al., 1997; Anderson et al., 1999; Anderson et al., 2001; Cobos et al., 2001; Marín and Rubenstein, 2001; Pleasure et al., 2000; Stühmer et al., 2002). Similarly, in Pleurodeles we were also able to detect an important number of GABA-expressing cells in pallial regions, most likely arising in the subpallium, as in other tetrapods.

The Isl 1 gene belongs to the family of LIM-homeodomain genes which possess prominent expression and function in the nervous system, playing crucial roles in control of cell fate specification, survival and differentiation, and axonal projection patterns in vertebrates (reviewed in Bach, 2000; Hobert and Westphal, 2000; Retaux and Bachy, 2002). During development, they are strongly expressed in highly specific neuromeric territories with similar patterns in the brain of vertebrates (Abellán et al., 2006; Alunni et al., 2004; Bachy et al., 2001; Lim and Golden, 2002; Moreno et al., 2004; Moreno et al., 2005; Osorio et al., 2005; Osorio et al., 2006; Rétaux et al., 1999). In particular, Isl1 expression in the telencephalon is restricted to the LGE during development (Stenman et al., 2003) and it was associated with the cholinergic phenotype in several neural systems (Ericson et al., 1992; Galli-Resta et al., 1997, Moreno and González, 2006; Wang and Liu, 2001), and also with the control of the axon guidance in the telencephalon (López-Bendito et al., 2006). In Pleurodeles, similar to that described in Xenopus, it is expressed by large numbers of striatal cells, always avoiding the ventricular surface.

Concerning the distribution of NOS, two main expressing cell groups can be distinctly identified in the telencephalon of Pleurodeles (González

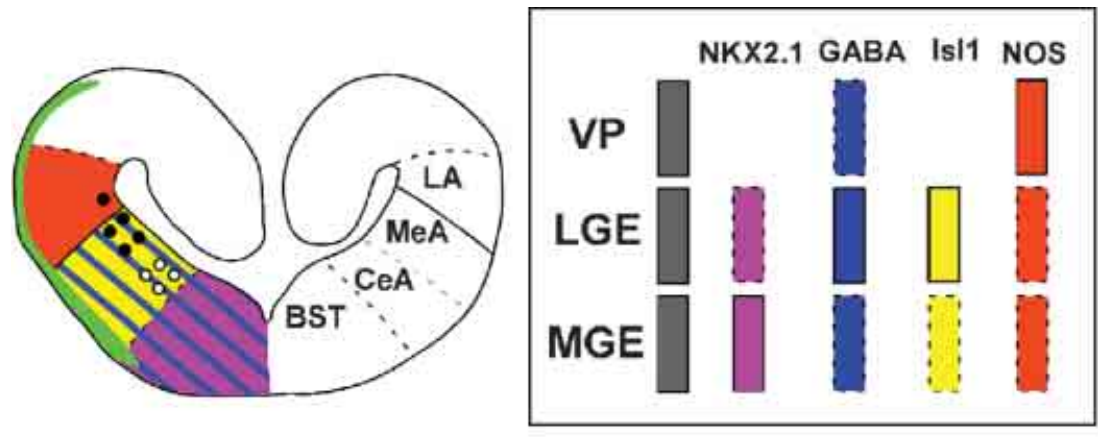

\begin{tabular}{|c|c|}
\hline $\begin{array}{l}\text { NOS IsI1 a Nkx2.1 a GABA } \\
\text { O Olfactory projection } \\
\text { - Main Hypothalamic projection cells } \\
\text { O Long-descending projection cells }\end{array}$ & $\begin{array}{l}\text { High cell population } \\
\text { scattered cells }\end{array}$ \\
\hline
\end{tabular}

Figure 7. Summary diagram of a transverse section in the Pleurodeles caudal telencephalon showing the pattern of expressions and connections found in the present study (left side of the section) and the proposed subdivision of the amygdaloid complex (right side of the section). 
et al., 1996; Moreno et al., 2002, present results). The first corresponded to the recently identified ventral pallium of anurans (Brox et al., 2004; Moreno et al., 2004), whereas the second group is located in the caudal striatal region. Notably in anurans, the large NOS-positive cells in the caudal striatal territory provided a guide for the identification of the CeA, otherwise indistinguishable (Moreno and González, 2005a).

In summary, the chemoarchitecture analyzed in the present study clearly delineate the boundaries of the main telencephalic subdivisions: the pallial/subpallial boundary, based on the combination of NOS and IsI1 or GABA, and the LGE/MGE boundary, based on the combination of Nkx2.1 and IsI1. Furthermore, the present data evidence a ventropallial region in a position that was already distinct on the basis of its hodology and that was named "striatopallial transition area, SPTA" by Marín and collaborators (Marín et al., 1997a; Marín et al., 1997b). Finally, the scattered Nkx2.1 and GABA immunoreactive cells in striatal and pallial regions, respectively, strongly support the notion that in the urodele telencephalon important migratory movements across different regions may occur during development, as in other tetrapods.

\section{The amygdaloid complex}

In recent years, the amygdaloid complex in anurans has been reevaluated, and three main regions have been re-defined: the new named LA, that corresponds with the ventral portion of the ventral pallium and shares many hodological features with the amygdaloid ventropallial derivatives of the basolateral complex of amniotes (Moreno and González, 2004), the medial amygdala (MeA), that constitutes the main secondary vomeronasal center that strongly projects to the ventral hypothalamus and possess a subpallial origin (Moreno and González, 2003; Moreno and González, 2007b), and the CeA, a striatal region that constitutes the autonomic amygdaloid subdivision as in amniotes (Moreno and González, 2005a; Moreno and González, 2006).

In the case of $P$. waltl, an amygdaloid area called "amygdala pars lateralis" (Northcutt and Kicliter, 1980) was defined and now we know that expresses GABA and Isl1, possesses Nkx2.1 scattered cells, and receives a vomeronasal/olfactory projection that could be processed and relayed to the ventral hypothalamus. The combination of all the present data showed this amygdaloid area to be a subpallial region, in contrast to its previously proposed pallial nature (Northcutt and Kicliter, 1980). Thus, based on the present data the "amygdala pars lateralis" (currently MeA) of urodeles corresponds to a region rich in GABA and Isl1-expressing cells (see Figure 7), and ventral to the NOS-rich ventropallial region (present results), like in anurans (Moreno and González, 2004). In addition, the present results clearly show the strong relationship of this area with the hypothalamus and how the olfactory/vomeronasal information may be relayed to the hypothalamus, like in anurans (Moreno and González, 2003; Moreno and González, 2004). Notably, this area could be further subdivided and include the recently named "caudal amygdala" of Laberge and Roth (2005), a region demonstrated to receive important vomeronasal information. Taking into account all these data, this area that constitutes a secondary olfactory/vomeronasal area that projects to the ventral hypothalamus and expresses subpallial markers is proposed as the MeA of urodeles, by comparison with the similarly identified area in anurans and amniotes (Moreno and González, 2006). To re-name this area would serve to help the establishment of putative homologies with its counterparts in anurans and amniotes, facilitating the study of the evolutionary relationships in the amygdaloid complex. Of note, a recent study in mammals based on the analysis of developing expression patterns, it has been proposed that the MeA consists of subdivisions or cell groups that derive from subpallial (derivatives from the MGE, the anterior peduncular area, and possibly the commissural preoptic area) ventral pallium, or extratelencephalic progenitor domains (García-López et al., 2008). In Pleurodeles, it is clear that a similar approach through development would be needed before establishing final conclusions. However, given the expression of Nkx2.1 and NOS (present results;
Moreno et al., 2002) and the data from anurans during development (González et al., 2002a; González et al., 2002b; López and González, 2002; Moreno et al., 2004; Moreno and González, 2007b), we can state at least that the amphibian MeA is an olfactory/vomeronasal structure situated in the pallio-subpallio boundary much more complex than previously thought, containing cells expressing subpallial markers and, from late developmental stages, cells that express some pallial markers. Therefore, also in amphibians the MeA could also be constituted by subdivisions or cell groups arising in different areas but the origin of the nucleus, with the data gathered until now, seems subpallial (Moreno and González, 2007b). Furthermore, the available data strengthen its comparison with the MeA of mammals and not with the posteriomedial cortical amygdala.

Previous studies from our laboratory (Marín et al., 1997a; Marín et al., 1997b, 1998a) showed the important features shared by urodeles and anurans in the basal ganglia, both possessing a distinct comparable caudal portion of the striatum and a region between the striatum and the pallium, called at that moment the SPTA (in Marín et al., 1997a; Marín et al., 1997b). These regions likely corresponded, as already demonstrated in anurans, with the current CeA and ventral portion of the ventral pallium, respectively (present results; Moreno and González, 2004; Moreno and González, 2005a). Of note, Laberge and Roth (2005) proposed that the region of the SPTA forms with the caudal amygdala an extended vomeronasal amygdala. In Pleurodeles, this ventral portion of the ventral pallium receives important olfactory projection, but never vomeronasal (Schmidt and Roth, 1990, present results) and possesses an important connections with the striatum (Marín et al., 1997a; Marín et al., 1997b), similar to that described in the LA of anurans (Moreno and González, 2004). However, in Pleurodeles, this region showed a small projection to the ventral hypothalamus, with only some scattered projection cells (present results), while in anurans the LA constitutes, along with the MeA, the main hypothalamic projection center in the anuran telencephalon through the stria terminalis (Moreno and González, 2005b). Traditionally in amphibians, this pallial part was considered as the ventral part of the lateral pallium (Neary, 1990), but its different nature has long been proposed (Bruce and Neary, 1995; Marín et al., 1997a; Marín et al., 1997b), and in anurans, the lateral part of the amygdala was first located within the ventral lateral pallium on chemoarchitectural grounds (Marín et al., 1998a). In agreement with this, and based on x-Lhx9, x-GAD67, xDII-4 expression, the LA was identified in Xenopus laevis in the ventral portion of the ventral pallium (Brox et al., 2003; Brox et al., 2004; Moreno et al., 2004). In addition, defining features of the ventral pallium in amniotes are its position deep to the lateral olfactory tract and dorsal to striatal territories (Puelles et al., 2000), criteria that are in full agreement with the situation in anurans (Moreno and González, 2006) and in Pleurodeles (present results). Therefore, the identification of the LA within the ventral pallium of Pleurodeles gains support not only because of its important NOS staining but also because of its olfactory input, position, and GABA-expressing cells (present results; Brox et al., 2003; Moreno et al., 2004). The shared chemoarchitecture and ventral pallial nature prompted the comparison between the LA in anurans, and now urodeles, and ventropallial derivatives of the basolateral components of the amygdala in mammals, or the posterior dorsal ventricular ridge in reptiles (Marín et al., 1998a; McDonald et al., 1993; Moreno and González, 2006; Muñoz et al., 1996; López and González, 2002; Olmos et al., 2005; Smeets et al., 1997).

Otherwise, Laberge and Roth (2005) proposed that the "vcp" could be compared to the mammalian basolateral amygdala and CeA, being a putative case of homoplasy due to the different embryological origin (present results). Our results in Pleurodeles clearly demonstrate the pallidal nature of this area, based on the Nkx2.1 expression pattern, making it impossible to establish homologies with the basolateral amygdala (with a pallial nature) or with the CeA (with a striatal origin). In contrast, we think, based on our previous results in Pleurodeles (Marín et al., 1997a; Marín et al., 1997b; Marín et al., 1997c) and the 
connections showed in Plethodon (Laberge and Roth, 2005) that this area is comparable to the bed nucleus of the stria terminalis (BST) proposed in anurans in a similar area (Marín et al., 1998a; Marín et al., 1998b), but more specific tract-tracing studies about this area are needed to confirm its homology.

In relation to the identification of the $\mathrm{CeA}$, long descending projections to the parabrachial area and spinal cord have been detected arising from the distinct caudal striatal region defined in our study (present results; Laberge and Roth, 2005; Marín et al., 1997b; Sánchez-Camacho et al., 2001). In addition, in this area the presence of large NOS immunoreactive cells and abundant GABAergic cells has been detected, comparable to that found in the anuran CeA (Moreno and González, 2006). The results found in Plethodon (Laberge and Roth, 2005) showed that this area, a striatal area at telencephalic levels rostral to the anterior commissure, possesses connections with caudal centers, like the rostral medulla, showing important anterograde and retrograde labeling after biocytin applications at these caudal levels. Thus, we propose that this area is likely to be the autonomic amygdaloid region of the Pleurodeles telencephalon, the CeA.

\section{CONCLUSION}

Our results demonstrate that the telencephalon of Pleurodeles possesses comparable subdivisions to those described in other tetrapods, demonstrating the existence of a ventral pallium and suggesting migratory movements, thus showing a telencephalon having a much more complex organization than previously thought. In addition, based on the present results we can propose three amygdaloid regions comparable to those demonstrated in anuran amphibians (Moreno and González, 2006). A ventropallial derivative, the LA, which receives the olfactory information, the MeA, the main secondary vomeronasal center that strongly projects to the ventral hypothalamus and possesses a subpallial origin, and the CeA, a striatal area that constitutes the autonomic amygdaloid subdivision as in amniotes.

Thus, the amygdaloid complex of all tetrapods would share four basic features: (1) it is topographically situated in the ventrolateral caudal telencephalic hemispheres; (2) it is formed by pallial and subpallial derivatives; (3) it is strongly related with the olfactory and vomeronasal systems; and (4) it is the origin of important hypothalamic projections. The present results corroborate these features in a urodele amphibian and support the hypothesis that, as a consequence of the evolutionary increase in the size of the pallial areas and the acquisition of large new areas, the current spatial arrangement of the amygdala in amniotes, and specially in mammals, would be the result of a re-localization of the central, medial (autonomic, vomeronasal), and basolateral (primary olfactory) nuclei, which in the ancestral condition occupied a ventrolateral position in the caudal telencephalon, as it can be still found in living amphibians (Moreno and González, 2006, present results). Thus, the amygdala in anamniotes might be composed by the most conserved amygdaloid regions, while in amniotes the amygdala would be the sum of evolutionary old centromedial and basolateral regions and cortical new regions, which would be missing in the amphibian brain.

\section{CONFLICT OF INTEREST STATEMENT}

The authors declare that the research was conducted in the absence of any commercial or financial relationships that could be construed as a potential conflict of interest.

\section{ACKNOWLEDGMENTS}

The work was supported by the Spanish Ministry of Science and Technology. Grant number: BFU2006-01014/BFI.

\section{REFERENCES}

Abellán, A., Vernier, B., Retáux, S., and Medina, L. (2006). Expression of LIMhomeodomain genes in chicken telencephalon helps to identify the pallial amygdala in birds. Federation of European Forum. FENS Abstr. 3, A230.1.
Alunni, A., Blin, M., Deschet, K., Bourrat, F., Vernier, P., and Rétaux, S. (2004). Cloning and developmental expression patterns of DIx2, Lhx7 and Lhx9 in the medaka fish (Oryzias latipes). Mech. Dev. 121, 977-983.

Anderson, S. A., Qiu, M., Bulfone, A., Eisenstat, D. D., Meneses, J., Pedersen, R., and Rubenstein, J. L. (1997). Mutations of the homeobox genes Dlx-1 and Dlx-2 disrupt the striatal subventricular zone and differentiation of late born striatal neurons. Neuron 19, 27-37.

Anderson, S., Mione, M., Yun, K., and Rubenstein, J. L. (1999). Differential origins of neocortical projection and local circuit neurons: role of Dlx genes in neocortical interneuronogenesis. Cereb. Cortex 9, 646-654.

Anderson, S. A., Marin, O., Horn, C., Jennings, K., and Rubenstein, J. L. (2001). Distinct cortical migrations from the medial and lateral ganglionic eminences. Development 128, 353-363.

Bach, I. (2000). The LIM domain: regulation by association. Mech. Dev. 91, 5-17.

Bachy, I., and Rétaux, S. (2006). GABAergic specification in the basal forebrain is controlled by the LIM-hd factor Lhx7. Dev. Biol. 291, 218-226.

Bachy, I., Vernier, P., and Rétaux, S. (2001). The LIM-homeodomain gene family in the developing Xenopus brain: conservation and divergences with the mouse related to the evolution of the forebrain. J. Neurosci. 21, 7620-7629.

Bachy, I., Berthon, J., and Rétaux, S. (2002). Defining pallial and subpallial divisions in the developing Xenopus forebrain. Mech. Dev. 117, 163-172.

Brox, A., Puelles, L., Ferreiro, B., and Medina, L. (2003). Expression of the genes GAD67 and distal-less- 4 in the forebrain of Xenopus laevis confirms a common pattern in tetrapods. J. Comp. Neurol. 461, 370-393.

Brox, A., Puelles, L., Ferreiro, B., and Medina, L. (2004). Expression of the genes Emx1, Tbr1, and Eomes (Tbr2) in the telencephalon of Xenopus laevis confirms the existence of a ventral pallial division in all tetrapods. J. Comp. Neurol. 474, 562577.

Bruce, L. L., and Neary, T. J. (1995). The limbic system of tetrapods: a comparative analysis of cortical and amygdalar populations. Brain Behav. Evol. 46, 224-234.

Bulfone, A., Puelles, L., Porteus, M. H., Frohman, M. A., Martin, G. R., and Rubenstein, J. L. (1993). Spatially restricted expression of Dlx-1, Dlx-2 (Tes-1), Gbx-2, and Wnt-3 in the embryonic day 12.5 mouse forebrain defines potential transverse and longitudinal segmental boundaries. J. Neurosci. 13, 3155-3172.

Carrillo, G. D., and Doupe, A. J. (2004). Is the songbird Area X striatal, pallidal, or both? An anatomical study. J. Comp. Neurol. 473, 415-437.

Cobos, I., Shimamura, K., Rubenstein, J. L., Martinez, S., and Puelles, L. (2001). Fate map of the avian anterior forebrain at the four-somite stage, based on the analysis of quail-chick chimeras. Dev. Biol. 239, 46-67.

Corbin, J. G., Rutlin, M., Gaiano, N., and Fishell, G. (2003). Combinatorial function of the homeodomain proteins Nkx2.1 and Gsh2 in ventral telencephalic patterning. Development 130, 4895-4906.

Endepols, H., Muhlenbrock-Lenter, S., Roth, G., and Walkowiak, W. (2006). The septal complex of the fire-bellied toad Bombina orientalis: chemoarchitecture. J. Chem. Neuroanat. 31, 59-76.

Endepols, H., Helmbold, F., and Walkowiak, W. (2007). GABAergic projection neurons in the basal ganglia of the green tree frog (Hyla cinerea). Brain Res. 1138, 76-85.

Ericson, J., Thor, S., Edlund, T., Jessell, T. M., and Yamada, T. (1992). Early stages of motor neuron differentiation revealed by expression of homeobox gene Islet-1. Science 256, 1555-1560.

Fritzsch, B. (1980). Retinal projections in European Salamanridae. Cell Tissue Res. 213, 325-341.

Galli-Resta, L., Resta, G., Tan, S. S., and Reese, B. E. (1997). Mosaics of islet-1expressing amacrine cells assembled by short-range cellular interactions. J. Neurosci. 17, 7831-7838.

García-López, M., Abellán, A. Legaz, L, Rubenstein, J. L. R., Puelles, L., and Medina, L. (2008). Histogenetic compartments of the mouse centromedial and extended amygdala based on gene expression patterns during development. J. Comp. Neurol. 506, 46-74.

González, A., Muñoz, A., Muñoz, M., Marín, 0., Arevalo, R., Porteros, A., and Alonso, J. R. (1996). Nitric oxide synthase in the brain of a urodele amphibian (Pleurodeles walth) and its relation to catecholaminergic neuronal structures. Brain Res. 727, 49-64.

González, A., López, J. M., Sánchez-Camacho, C., and Marín, 0. (2002a). Regional expression of the homeobox gene NKX 2-1defines pallidal and interneuronal populations in the basal ganglia of amphibians. Neuroscience 114, 567-575.

González, A., López, J. M., and Marín, 0. (2002b). Expression pattern of the homeobox protein NKX 2-1in the developing Xenopus forebrain. Brain Res. Gene Expr. Patterns $1,181-185$.

Guirado, S., Davila, J. C., Real, M. A., and Medina, L. (1999). Nucleus accumbens in the lizard Psammodromus algirus: chemoarchitecture and cortical afferent connections. J. Comp. Neurol. 405, 15-31.

Hauptmann, G., and Gerster, T. (2000). Regulatory gene expression patterns reveal transverse and longitudinal subdivisions of the embryonic zebrafish forebrain. Mech. Dev. 91, 105-118.

Herbison, A. E., Simonian, S. X., Norris, P. J., and Emson, P. C. (1996). Relationship of neuronal nitric oxide synthase immunoreactivity to $\mathrm{GnRH}$ neurons in the ovariectomized and intact female rat. J. Neuroendocrinol. 8, 73-82.

Herrick, C. (1927). The amphbian forebrain. IV. The cerebral hemispheres of Amblystoma. J. Comp. Neurol. 43, 231-325.

Herrick, C. (1948). The brain of the tiger salamander Amblystoma tigrinum (Chicago, University of Chicago Press).

Hobert, 0., and Westphal, H. (2000). Functions of LIM-homeobox genes. Trends Genet. $16,75-83$. 
Katarova, Z., Sekerkova, G., Prodan, S., Mugnaini, E., and Szabo, G. (2000). Domainrestricted expression of two glutamic acid decarboxylase genes in midgestation mouse embryos. J. Comp. Neurol. 424, 607-627.

Kimura, S., Hara, Y., Pineau, T., Fernandez-Salguero, P., Fox, C. H., Ward, J. M., and González, F. J. (1996). The T/ebp null mouse: thyroid-specific enhancer-binding protein is essential for the organogenesis of the thyroid, lung, ventral forebrain, and pituitary. Genes Dev. 10, 60-69.

Laberge, F., and Roth, G. (2005). Connectivity and cytoarchitecture of the ventra telencephalon in the salamander Plethodon shermani. J. Comp. Neurol. 482, 176200.

Laberge, F., Muhlenbrock-Lenter, S., Grunwald, W., and Roth, G. (2006). Evolution of the amygdala: new insights from studies in amphibians. Brain Behav. Evol. 67, 177187.

Lanuza, E., Font, C., Martínez-Marcos, A., and Martínez-García, F. (1997). Amygdalohypothalamic projections in the lizard Podarcis hispanica: a combined anterograde and retrograde tracing study. J. Comp. Neurol. 384, 537-555.

Lazzaro, D., Price, M., de Felice, M., and Di Lauro, R. (1991). The transcription factor TTF1 is expressed at the onset of thyroid and lung morphogenesis and in restricted regions of the fetal brain. Development 113, 1093-1104.

Lim, Y., and Golden, J. A. (2002). Expression pattern of cLhx2b, cZic1 and cZic3 in the developing chick diencephalon. Mech. Dev. 115, 147-150.

López, J. M., and González, A. (2002). Ontogeny of NADPH diaphorase/nitric oxide synthase reactivity in the brain of Xenopus laevis. J. Comp. Neurol. 445, 59-77.

López-Bendito, G., Cautinat, A., Sánchez, J. A., Bielle, F., Flames, N., Garratt, A. N., Talmage, D. A., Role, L. W., Charnay, P., Marín, 0., and Garel, S. (2006). Tangential neuronal migration controls axon guidance: a role for neuregulin-1 in thalamocortical axon navigation. Cell 125, 127-142.

Marín, 0., and Rubenstein, J. L. (2001). A long, remarkable journey: tangential migration in the telencephalon. Nat. Rev. Neurosci. 2, 780-790.

Marín, 0., González, A., and Smeets, W. J. A. J. (1997a). Basal ganglia organization in amphibians: afferent connections to the striatum and the nucleus accumbens. $J$. Comp. Neurol. 378, 16-49.

Marín, 0., González, A., and Smeets, W. J. A. J. (1997b). Basal ganglia organization in amphibians: efferent connections of the striatum and the nucleus accumbens. $J$. Comp. Neurol. 380, 23-50.

Marín, 0., Smeets, W. J., and González, A. (1997c). Basal ganglia organization in amphibians: catecholaminergic innervation of the striatum and the nucleus accumbens. J Comp. Neurol. 378, 50-69.

Marín, 0., Smeets, W. J. A. J., and González, A. (1998a). Basal ganglia organization in amphibians: chemoarchitecture. J. Comp. Neurol. 392, 285-312.

Marín, 0., Smeets, W. J. A. J., and González, A. (1998b). Evolution of the basal ganglia in tetrapods: a new perspective based on recent studies in amphibians. Trends Neurosci. 21, 487-494.

Marín, 0., Anderson, S. A., and Rubenstein, J. L. (2000). Origin and molecular specification of striatal interneurons. J. Neurosci. 20, 6063-6076.

Marín, 0., Baker, J., Puelles, L., and Rubenstein, J. L. (2002). Patterning of the basa telencephalon and hypothalamus is essential for guidance of cortical projections. Development 129, 761-773.

Martínez-García, F., Novejarque, A., and Lanuza, E. (2006). Evolution of the amygdala in vertebrates. In Evolution of Nervous Systems , J. H. Kaas, ed. (Oxford, Academic Press), pp. 255-334.

McDonald, A. J., Payne, D. R., and Mascagni, F. (1993). Identification of putative nitric oxide producing neurons in the rat amygdala using NADPH-diaphorase histochemistry. Neuroscience 52, 97-106.

Medina, L., and Reiner, A. (1995). Neurotransmitter organization and connectivity of the basal ganglia in vertebrates: implications for the evolution of basal ganglia. Brain Behav. Evol. 46, 235-258.

Milán, F. J., and Puelles, L. (2000). Patterns of calretinin, calbindin, and tyrosinehydroxylase expression are consistent with the prosomeric map of the frog diencephalon. J. Comp. Neurol. 419, 96-121.

Moreno, N., and González, A. (2005a). Central amygdala in anuran amphibians: neurochemical organization and connectivity. J. Comp. Neurol. 489, 69-691.

Moreno, N., and González, A. (2005b). Forebrain projections to the hypothalamus are topographically organized in anurans: conservative traits as compared with amniotes. Eur. J. Neurosci. 21, 1895-1910.

Moreno, N., and González, A. (2006). The common organization of the amygdaloid complex in tetrapods: new concepts based on developmental, hodological and neurochemical data in anuran amphibians. Prog. Neurobiol. 78, 61-90.

Moreno, N., and González, A. (2007a). Evolution of the amygdaloid complex in vertebrates, with special reference to the anamnio-amniotic transition. J. Anat. 211 $151-163$.

Moreno, N., and González, A. (2003). Hodological characterization of the medial amygdala in anuran amphibians. J. Comp. Neurol. 466, 389-408.

Moreno, N., and González, A. (2004). Localization and connectivity of the lateral amygdala in anuran amphibians. J. Comp. Neurol. 479, 130.

Moreno, N., and González, A. (2007b). Development of the vomeronasal amygdala in anuran amphibians: hodological, neurochemical, and gene expression characterization. J. Comp. Neurol. 503, 815-831.

Moreno, N., López, J. M., Sánchez-Camacho, C., and González, A. (2002). Development of NADPH-diaphorase/nitric oxide synthase in the brain of the urodele amphibian Pleurodeles waltl. J. Chem. Neuroanat. 23, 105-121.

Moreno, N., Bachy, I., Rétaux, S., and González, A. (2004). LIM-homeodomain genes as developmental and adult genetic markers of Xenopus forebrain functional subdivisions. J. Comp. Neurol. 472, 52-72.
Moreno, N., Bachy, I., Rétaux, S., and González, A. (2005). LIM-homeodomain genes as territory markers in the brainstem of adult and developing Xenopus laevis. J. Comp. Neurol. 485, 240-254.

Muñoz, M., Muñoz, A., Marín, 0., Alonso, J. R., Arévalo, R., Porteros, A., and González, A. (1996). Topographical distribution of NADPH-diaphorase activity in the central nervous system of the frog, Rana perezi. J. Comp. Neurol. 367, 54-69.

Muñoz, M., Marín, 0., and González, A. (2000). Localization of NADPH diaphorase/nitric oxide synthase and choline acetyltransferase in the spinal cord of the frog, Rana perezi. J. Comp. Neurol. 419, 451-470.

Neary, T. J. (1990). The pallium of anuran amphibians. In Cerebral Cortex: Comparative Structure and Evolution of Cerebral Cortex, Part 1, Vol. 8A, E. G. Jones, and A. Peters, eds. (New York, Plenum Press), pp. 107-138.

Northcutt, R. G. (1981). Evolution of the telencephalon in non-mammals. Annu. Rev. Neurosci. 4, 301-350.

Northcutt, R. G. (1984). Evolution of the vertebrate central nervous system: patterns and processes. Am. Zool. 24, 701-716.

Northcutt, R. G. (1987). Lungfish neural characters and their bearing on sarcopterygian phylogeny. J. Morphol. Suppl. 1, 277-297.

Northcutt, R. G., and Kicliter, E. (1980). Organization of the amphibian telencephalon. In Comparative Neurology of the Telencephalon, S. 0. E. Ebbesson, ed. (Plenum New York, Publishing Corporation), pp. 203-255.

Olmos, J. L., Real, M. A., Medina, L., Guirado, S., and Davila, J. C. (2005). Distribution of nitric oxide-producing neurons in the developing and adult mouse amygdalar basolateral complex. Brain Res. Bull. 66, 465-469.

Osorio, J., Mazan, S., and Rétaux, S. (2005). Organisation of the lamprey (Lampetra fluviatilis) embryonic brain: insights from LIM-homeodomain, Pax and hedgehog genes. Dev. Biol. 288, 100-112.

Osorio, J., Megías, M., Pombal, M. A., and Rétaux, S. (2006). Dynamic expression of the LIM-homeodomain gene Lhx15 through larval brain development of the sea lamprey (Petromyzon marinus). Gene Expr. Patterns 6, 873-878.

Pleasure, S. J., Anderson, S., Hevner, R., Bagri, A., Marin, 0., Lowenstein, D. H., and Rubenstein, J. L. (2000). Cell migration from the ganglionic eminences is required for the development of hippocampal GABAergic interneurons. Neuron 28, $727-$ 740 .

Pombal, M. A., and Puelles, L. (1999). Prosomeric map of the lamprey forebrain based on calretinin immunocytochemistry, Nissl stain, and ancillary markers. J.Comp. Neurol. 414, 391-422.

Price, J. L., Slotnick, B. M., and Revial, M. F. (1991). Olfactory projections to the hypothalamus. J. Comp. Neurol. 306, 447-461.

Puelles, L., and Rubenstein, J. L. R. (2003). Forebrain gene expression domains and the evolving prosomeric model. Trends Neurosci. 26, 469-476.

Puelles, L., Milán, F. J., and Martínez-de-la-Torre, M. (1996). A segmental map of architectonic subdivisions in the diencephalon of the frog Rana perezi: acetylcholinesterase-histochemical observations. Brain Behav. Evol. 47, 279 310

Puelles, L., Kuwana, E., Puelles, E., Bulfone, A., Shimamura, K., Keleher, J., Smiga, S. and Rubenstein, J. L. R. (2000). Pallial and subpallial derivatives in the embryonic chick and mouse telencephalon, traced by the expression of the genes Dlx-2, Emx-1, Nkx-2 1, Pax-6, and Tbr-1. J Comp. Neurol. 424, 409-438.

Reiner, A., Brauth, S. E., and Karte, H. J. (1984). Evolution of the amniote basal ganglia Trends Neurosci. 7, 320-325.

Reiner, A., Medina, L., and Veenman, C. L. (1998). Structural and functional evolution of the basal ganglia in vertebrates. Brain Res. Brain Res. Rev. 28, 235 285

Retaux, S., and Bachy, I. (2002). A short history of LIM domains (1993-2002): from protein interaction to degradation. Mol. Neurobiol. 26, 269-281.

Rétaux, S., Rogard, M., Bach, I., Failli, V., and Besson, M. J. (1999). Lhx9: a novel LIMhomeodomain gene expressed in the developing forebrain. J. Neurosci. 19, 783793.

Roth, G. (1987). Visual behaviour in salamanders. Studies in brain function , Vol. 14, (Berlin Heidelberg New York, Springer-Verlag)

Roth, G., Dicke, U., and Nishikawa, K. (1992). How do ontogeny, morphology and physiology of sensory systems constrain and direct the evolution of amphibians? Am. Nat. S105-S124.

Roth, G., Nishikawa, K., Naujoks-Manteuffel, C., Schmidt, A., and Wake, D. (1993). Paedomorphosis and simplification in the nervous system of salamanders. Brain Behav. Evol. 42, 137-170.

Royce, G., and Northcutt, R. G. (1969). Olfactory bulb projections in the tiger salamander (Amblystoma tigrinum) and the bullfrog (Rana catesbeiana). Anat. Rec. 163, 254.

Sánchez-Camacho, C. Marín, 0., Ten Donkelaar, H. J., and González, A. (2001). Descending supraspinal pathways in amphibians. I. A dextran amine tracing study of their cells of origin. J. Comp. Neurol. 434, 186-208.

Schmidt, A., and Roth, G. (1990). Central olfactory and vomeronasal pathways in salamanders. J. Hirnforsch. 31, 543-553.

Shimamura, K., and Rubenstein, J. L. (1997). Inductive interactions direct early regionalization of the mouse forebrain. Development 124, 2709-2718.

Smeets, W. J., Alonso, J. R., and González, A. (1997). Distribution of NADPH-diaphorase and nitric oxide synthase in relation to catecholaminergic neuronal structures in the brain of the lizard Gekko gecko. J. Comp. Neurol. 377, 121-141.

Smith Fernández, A., Pieau, C. Repérant, J., Boncinelli, E, and Wassef, M. (1998). Expression of the Emx-1 and Dlx-1 homeobox genes define three molecularly distinct domains in the telencephalon of mouse, chick, turtle and frog embryos: implications for the evolution of telencephalic subdivisions in amniotes. Development 125, 2099-2111. 
Stenman, J., Yu, R. T., Evans, R. M., and Campbell, K. (2003). Tlx and Pax6 co-operate genetically to establish the pallio-subpallial boundary in the embryonic mouse telencephalon. Development 130, 1113-1122.

Stühmer, T., Anderson, S. A., Ekker, M., and Rubenstein, J. L. (2002). Ectopic expression of the Dlx genes induces glutamic acid decarboxylase and Dlx expression. Development 129, 245-252.

Sussel, L., Marín, 0., Kimura, S., and Rubenstein, J. L. (1999). Loss of Nkx2.1 homeobox gene function results in a ventral to dorsal molecular respecification within the basal telencephalon: evidence for a transformation of the pallidum into the striatum. Development 126, 3359-3370. ten Donkelaar, H. J. (1998). Anurans. In The Central Nervous System of Vertebrates , R. Nieuwenhuys, H. J. ten Donkelaar, and C. Nicholson, eds. (London, Springer), pp. 1151-1314.

Wang, H. F., and Liu, F. C. (2001). Developmental restriction of the LIM homeodomain transcription factor Islet-1 expression to cholinergic neurons in the rat striatum. Neuroscience 103, 999-1016.

Wullimann, M. F., and Puelles, L. (1999). Postembryonic neural proliferation in the zebrafish forebrain and its relationship to prosomeric domains. Anat. Embryol. (Berl) 199, 329-348. 